\title{
DETERMINATION OF A TASK'S VALIDITY IN THE MARINE ENGINE ROOM OPERATING PROCESS
}

\author{
Piotr Kaminski \\ Faculty of Marine Engineering \\ Gdynia Maritime University \\ Gdynia, Poland \\ E-mail: pkam@am.gdynia.pl
}

\begin{abstract}
The frequent causes of ships' detentions by port authorities are abnormalities of marine power plant functioning. Each extended ship lay time in port results in a waste of ship operating time thus costs rise to ship owners. This is connected with improper marine power plant management. In order to avoid this, a ship engineer should have at his disposal computer aided system supporting him in the managing of the marine power plant. Such a system can be worked out on the condition that a mathematical model, which represents the decision - making process of an engineer has been built. One element of the decision making process in managing the marine engine room is to determine how important is each of the tasks which the operators have to do. This estimation is the base to choose the most important tasks and make optimal schedule with them. The present work shows the approach to the rating method of operating tasks using AHP method. Based on practice, a hierarchic structure of factors influencing a tasks validity in the engine room operating process was made. Next a preliminary questionnaire was conducted, which put questions to the experts as chief engineers next. This enabled to define numerical values of suitable coefficients influencing on the validity of operating tasks. The equation contains this all coefficients permit to determinate numerical values of an operating task's validity in given engine room operating processes.
\end{abstract}

Keywords: engine room, task scheduling

\section{Introduction}

According to many experts, reaching correct management of a marine power plant involves great difficulties to decision-making people like ship chief engineers. This is caused i.e. by:

- increasing number of automated ship systems,

- multiple number of operational processes executed in parallel,

- lack of appropriate information making it possible to quickly master systems and task planning,

- frequent changes of staff members,

- increasing number of requirements for safety of persons, ship and environment.

Moreover, changing international maritime law imposes many additional tasks dealing not only with new procedures connected with safety at sea but also with their detailed 
documentation. Such a state leads to a situation in which decision-making is more and more difficult and the knowledge and experience of ship engineers may appear insufficient. In such conditions making a decision dealing with power plant management may be incorrect or irrational and in consequence cause various losses, e.g. loss of ship service time leading this way to increasing overall cost of ship operation. In order to eliminate such situations, ship engineers should have at their disposal software (computer system) which could be a ,tool” aiding them in organizing the marine power plant management process. Such a system would collect information concerning realization of all operations in power plant or make use of the data bases of already functioning the information systems, analyze any limitations associated with their realization and finally advise ship engineer on which tasks and in which sequence they have to be realized. In marine power plants, a staff often consisted of several people performs operations resulting from the realization of many tasks of different time horizons, realized in parallel. This requires a chief engineer to make rational decisions concerning the exact determination of the kind, range, sequence and executors of operations. To make such decisions it is necessary to collect and processes a lot of information. All this information may appear or be used during decision making process in various service stages of a ship. From the operational point of view, the best (optimal) plan of the tasks which are necessary to be realized in a given operational situation constitutes the solution of the decision problem faced by the ship engineer. Analyzing situations in which the ship engineer may be forced to solve the presented decision problem, one can distinguish several, different ways of its formulation. For instance, the first situation of the kind is that in which a ship continues a long sea voyage. In such a situation there are no strict time limitations as to realization of the marine power plant operation process, as well as to particular operational tasks. So, the decision problem can be formulated as a planning process without any time limitations. However the tasks should be effectively planned with the use of available personnel and material resources as well as with taking into account the instant of realization of a given task, imposed by external factors such as: requirements resulting from regulations given by producers of ship machines and devices, classification societies, port control (PSC, FSC), etc.

The other situation is that in which strict time limitations are present such as e.g.: during a ship staying in a port where the ship's strict departure time is known and the number of the tasks to be realized is usually much greater than that possible for the staff of the power plant. In such a situation the chief engineer must make a decision regarding which of the operational tasks should be made during the time being at his disposal and which could be postponed to another time, as well as who should be assigned to execute particular tasks. In such a moment, making incorrect decisions can cause non-fulfilment of the tasks, that consequently may result e.g.: in stopping the ship by port control (PSC, FSC) or subsequently in breaking the normal process of marine power plant operation (e.g. black-out). The decision problem in such situation can be formulated as the choice of the crucial tasks from the point of view of the marine power plant operation, and planning them in such a way as to make use of the available time most effectively.

Another situation is that in which both the strict time limitations are present and one aims at the best making use of the available resources, where the features of the first above described situation and the other one are combined in a sense. Such formulation of the decision problem may concern the situation when a ship undergoes repair in a shipyard.

In ship operation many other situations (ship service states) can also happen such as e.g.: lying at anchor, manoeuvres, canal passing etc, in which the chief engineer may be forced to take decisions dealing with planning the operational tasks. However, such states International Journal of the 2 Vol. 3 Issue 12011 Analytic Hierarchy Process ISSN 1936-6744 
constitute a very small part of the overall operational time of a ship as they appear very rarely during its service process, or a situation requires to promptly make a decision regarding a way of action to be undertaken (e.g. manoeuvres in port) where possible making use of a computer system is not rational. In this connection for further considerations only two - out of the presented service states - namely: sea voyage and staying in port, are taken into account. In the general theory of decision making the decision problem is such a situation in which the decision maker faces necessity of choosing one - out at least two possible - variants of acting. In the marine power plant the chief engineer must take a decision on which of the acting variants (sets of sequenced operations) would be the best from the point of view of ship service. According to the definition of the problem faced by the ship engineer, he must, out of all operations to be executed, select and sequence as well as assign (to respective members of machinery crew) the most important ones in a given operational situation taking into account all relevant conditions and limitations. A very important phase of this process is to determine the importance (validity) of all operating tasks which is the background to make an optimal schedule of it.

In the process of decision making by ship engineer dealing with scheduling the operational tasks to power plant staff members, the following four main phases should be distinguished:

- collecting and processing all available and necessary data,

- selecting the tasks whose realization is constrained by all possible operational limitations as well as ambient conditions in which a given decision is made [Kaminski, 2006],

- determine the validity of selected operating tasks,

- assigning the earlier selected tasks to power plant crew members, in compliance with their competences so as to obtain the best schedule from the operational point of view [Downarowicz et al., 2000], [Kaminski 2004].

In this work only the third presented stage is considered - determining of validity to selected operating tasks in the marine power plant. The remaining phases of these processes were earlier described by an author in another papers [Kaminski et al. 2003], [Kaminski 2007], [Saaty 1980].

\section{Factors influencing the validity of operating tasks}

The process of optimal scheduling is leaning on the operating tasks. They must be priorities under in relation to validity each of them in the operation process in the marine power plant in a given situation.

The task's scheduling process in the engine room runs most often in conditions, when the number of tasks considerably tops the possibility of their realization by machine crew. The stops of ships in ports are shorter and shorter, sometimes a few hours. The number of works (tasks) which must be executed is larger and larger and the relatively small number of machine staff is often limited. This is the reason that the decision-maker in the engine room chief engineer, has to choose from huge tasks collection those which completion is possible in given conditions, as well as those which are the most important fro a given operating point of view. Such selection could be executed when the tasks are priorities (rated) under regard of their validity. For rating operating tasks there was a necessity to define criterions and factors which described the tasks and have implication to operating processes in the engine room. 
The validity of single tasks was proposed as a function of this:

$$
T v=f\left(C_{i}\right) \quad\left\{C_{i}: i=1,2, \ldots, n\right\}
$$

where:

$T v$ - the task validity,

$C_{i}$ - the factors influencing task validity.

Those factors were a definite basis on the review and profile of the operating tasks and practice experience of author and experts [Kaminski 2006], [Tarelko and Podsiadlo2006]. They were partite on 6 general factors $\mathrm{Ci}$ as well as from 2 to 4 detailed factors cij for every one general factor. Those Factors were definite in the following way:

- $\mathrm{C} 1$ - the factor related with the way of generating the task - the detailed factors:

○ by outside impose,

○ by breakdown,

- planned,

- $\mathrm{C} 2$ - the factor related with time - the detailed factors:

o deadline of the task executed,

$\circ$ repetition frequency,

○ task executed time,

- $\mathrm{C} 3$ - the factor related with validity of device - the detailed factors:

$\circ$ 1st engineer,

2nd engineer,

$\circ$ 3rd engineer,

$\circ$ 4th engineer,

- $\mathrm{C} 4$ - the factor related with possibility to omission of the engine room device in the operating process - the detailed factors:

$\circ$ number of devices,

- avoidance of devices in operating process,

- C5 - the factor related with possibility of shifting of the task execution - the detailed factors:

$\circ$ the operation stage of the ship,

$\circ$ the operation stage of the engine room,

- $\mathrm{C} 6$ - the factor related with the functional scope of operating task - the detailed factors (following by IMO - International Maritime Organization):

$\circ$ operation,

○ maintenance,

○ safety,

○ provision.

In this way the factors were qualified, but there is no information about their real or mathematical influence on the operating task validity. Therefore it was necessary to analyze what permitted to attribute all factors to some mathematical feature like coefficients of factor weight.

\section{Prioritizations of validity in literature}


The validity estimation is an integral part of overall decision making analyses. It is a process of weighting alternatives (options), selecting the most appropriate action, and integrating the results with engineering data, social, economic, and political concerns to make an acceptable decision.

There is a many ways to solve the problem of prioritizations or classification (cluster analysis, neighbor joining). The most frequently are used a methods like:

- taxonomy methods,

- multi-criteria decision making methods.

The aims of numerical taxonomy is to create a taxonomy using numeric algorithms like cluster analysis. Although intended as an objective classification methods, in practice the choice and weighing of morphological characteristics is often guided by available methods and research interests. Furthermore, the general consensus has become that the taxonomic classification should reflect evolutionary processes. Mathematically, a hierarchical taxonomy is a tree structure of classifications for a given set of objects [Suryanto and Compton, 2006], [Kukula 2000], [Ficon 2006].

To attribute the weight coefficients of individual factors it was necessary to use the experts' opinions and preferences. For the efficient and objectively execution of analysis which permit to measures of the validity factors, it required the use of advanced multicriterions decision-making (MCDM) methods. To the MCDM methods belongs, for example, Analytic Hierarchy Process, Analytic Network Process, Inner Product of Vectors, Multi-Attribute Value Theory, Multi-Attribute Utility Theory, Multi-Attribute Global Inference of Quality, Goal Programming, ELECTRE, etc.

One of the classified methods under utility theory is the Analytic Hierarchy Process (AHP). AHP has proved to be one of the most widely applied MCDM methods [Vaidya and Kumar 2006]. There is a growing list of publications on the application of AHP method in civil, environmental engineering likewise sporadic in marine engineering; e.g., [Holguin-Veras 1993], [Khasnabis et al. 2002], [Dey 2002], [Ziara et al. 2002], [Sadiq 2001], etc.

The approach developed for this study consolidates the experience and knowledge based on marine power plant operating and troubleshooting.

\section{Weight coefficients determination method to factors influence on the operating task validity}

Although performance measures are used very widely, the interpretation of the meaning of the performance measures is often able to be difficult. Moreover, the feedback of the performance level given by the performance measures should be utilized in the strategy planning process. In this paper is proposed an AHP method [Witkowska 2002] - based approach for supporting the performance measurement process and making it more effective by helping to understand the internal and external factors that have had or will have an impact on the operating process in the marine power plant. This method links in a rational way two approaches of decision-making: the intuition-logical data analysis and numeric data handling. The result of such expert advices' processing is accepted as a solution of the problem of the factors measures (weight).

Gain over the experts' knowledge in areas of a task's scheduling and engine room operating permits to attribute of influence every factor on task validity. The general coefficient of validity of an operating task was accepted with some foundations: 
- there exists the collection of partial coefficients $C_{i}, c_{i j}\{i=1,2, \ldots, 6 ; j=1,2,3,4\}$, each coefficient describe an individual factor (general and detailed) the task validity depends on it,

- the value of main and detailed factor weight coefficients $W C_{i}, w c_{i j}\{i=1,2, . ., 6 ; j$ $=1,2,3,4\}$ are defined based on the expert's knowledge,

- there exists an easy way to aggregation of the factor weight coefficients.

If the validity of task comparison would be possibly that there is need to integrating all factors and ascriptitious all of them weight coefficients in some global indicator of operating tasks validity $V I$ for each task. That the operating tasks validity indicator $V I$ has been clear cut and comparable for the all tasks it could be some product function consist factor coefficients $C_{i}, c_{i j}$ and factor weight coefficients $W C_{i}, w c_{i j}$ what shown equation 2 :

$$
V I=f\left(C_{i} \cdot W C_{i}, c_{i j} \cdot w c_{i j}\right) \quad\{i=1,2, \ldots, 6 ; j=1,2,3,4\}
$$

where:

$V I$ - the "global " validity indicator of operating tasks,

$C_{i}$ - the general factors coefficients,

$c_{i j}$ - the detailed factors coefficients,

$W C_{i}$ - the general factors weight coefficients,

$w c_{i j}$ - the detailed factors weight coefficients.

The detailed factor coefficients $c_{i j}$ described only information that the operating task have got some feature or not, therefore they could be represent by notation 0 or 1 :

$$
c_{i j}=\left\{\begin{array}{l}
1 \\
0
\end{array}\right\}
$$

The coefficients of general factors $C_{i}$ always accept value 1 , then this element could be leaved out in the next step.

\subsection{The AHP methodology}

The Analytic Hierarchy Process (AHP) is a method of measurement for dealing with quantifiable and indefinable criteria that has been applied to numerous areas, developed by Thomas Saaty in the 1970's. Many uses of this method to support decision-making processes, in fields such as government, business, industry, healthcare and education, convince us of its usefulness, especially in situations when the experience of the judge is the main source of opinions or the estimations have a strongly subjective quality.

AHP provides a comprehensive and rational framework for structuring a decision problem for representing and quantifying its elements, for relating those elements to overall goals, and for evaluating alternative solutions [Downarowicz et al. 2000]. It is based on the following three principles: decomposition, comparative judgments, and the synthesis of priorities. AHP starts by decomposing a complex, multi-criteria problem into a hierarchy where each level consists of a few manageable elements that are then decomposed into another set of elements [Saaty 1980]. The second step is to use a measurement methodology to establish priorities among the elements within each level of 
the hierarchy. The third step in using AHP is to synthesize the priorities of the elements to establish the overall priorities for the decision alternatives.

For computing the priorities of the elements, a judgmental matrix is assumed as follows:

$$
A=\left[\begin{array}{cccc}
a_{11} & a_{12} & \ldots & a_{1 n} \\
a_{21} & a_{22} & \ldots & a_{2 n} \\
\ldots & \ldots & \ldots & \ldots \\
a_{n 1} & a_{n 2} & \ldots & a_{n n}
\end{array}\right]
$$

where $a_{i j}$ represents the pair-wise comparison rating between the element $i$ and element $\mathrm{j}$ of a level with respect to the upper level. The entries $a_{i j}$ are governed by the following rules: $a_{i j}>0$;

$$
a_{i j}>0 ; a_{i j}=1 / a_{j i} ; a_{j j}=1 \quad \forall i
$$

Following Saaty, the priorities of the elements can be estimated by finding the principal eigenvector w of the matrix $A$, that is:

$$
A W=\lambda_{\max } W
$$

When the vector $W$ is normalized, it becomes the vector of priorities of elements of one level with respect to the upper level. The $\lambda_{\max }$ is the largest eigenvalue of the matrix $A$.

In cases where the pair-wise comparison matrix satisfies transitivity for all pair-wise comparisons it is said to be consistent and it verifies the following relation :

$$
a_{i j}=a_{i k} a_{k j}
$$

Saaty has shown that to maintain reasonable consistency when deriving priorities from paired comparisons, the number of factors being considered must be less or equal to nine. AHP allows inconsistency, but provides a measure of the inconsistency in each set of judgments. The consistency of the judgmental matrix can be determined by a measure called the consistency ratio $(C R)$, defined as:

$$
C R=\frac{C I}{R I}
$$

where:

$C I$ - the Consistency Index, $R I$ - the Random Index.

Furthermore, average consistencies ( $R I$ values) of randomly generated matrices (table 2 ) were provided. $C I$ for a matrix of order $\mathrm{n}$ is defined as:

$$
C I=\frac{\lambda_{\max }-n}{n-1}
$$


In general, a consistency ratio of 0.1 or less is considered acceptable, this threshold is 0.08 for matrices of size four and 0.05 for matrices of size three. If the value is higher, the judgments may not be reliable and should be elicited again.

Table 1

The average consistencies of random matrices (RI values)

\begin{tabular}{|c|c|c|c|c|c|c|c|c|c|c|}
\hline$n$ Size & 1 & 2 & 3 & 4 & 5 & 6 & 7 & 8 & 9 & 10 \\
\hline$R I$ & 0.00 & 0.00 & 0.52 & 0.89 & 1.11 & 1.2 & 1.35 & 1.40 & 1.45 & 1.49 \\
\hline
\end{tabular}

\subsection{Decompositions of evaluation criteria}

To apply the AHP method to rating the factor's impact on validity of operating tasks in the engine room, it requires the executions of this factor's hierarchy (priority). The decomposing of the validity factors in the hierarchic structure permits us to estimate each factor individually, which makes the problem easier, than the assessment of all factors simultaneously. The proper hierarchy process of factors was realized by the defining of main and detailed factors division. According to this the factors receive a hierarchic structure compatible with Saaty's theory (fig.1):

- high-level goal of the analysis - the "global" validity indicator of operating tasks $(V I)$,

- second-level, multi criteria - presented by the six general factors $C_{i}$,

- third-level, sub-criteria - presented by the detailed factors $c_{i}$,

- low-level - individual operating tasks $t_{i}$, which are estimated by general and detailed factors.

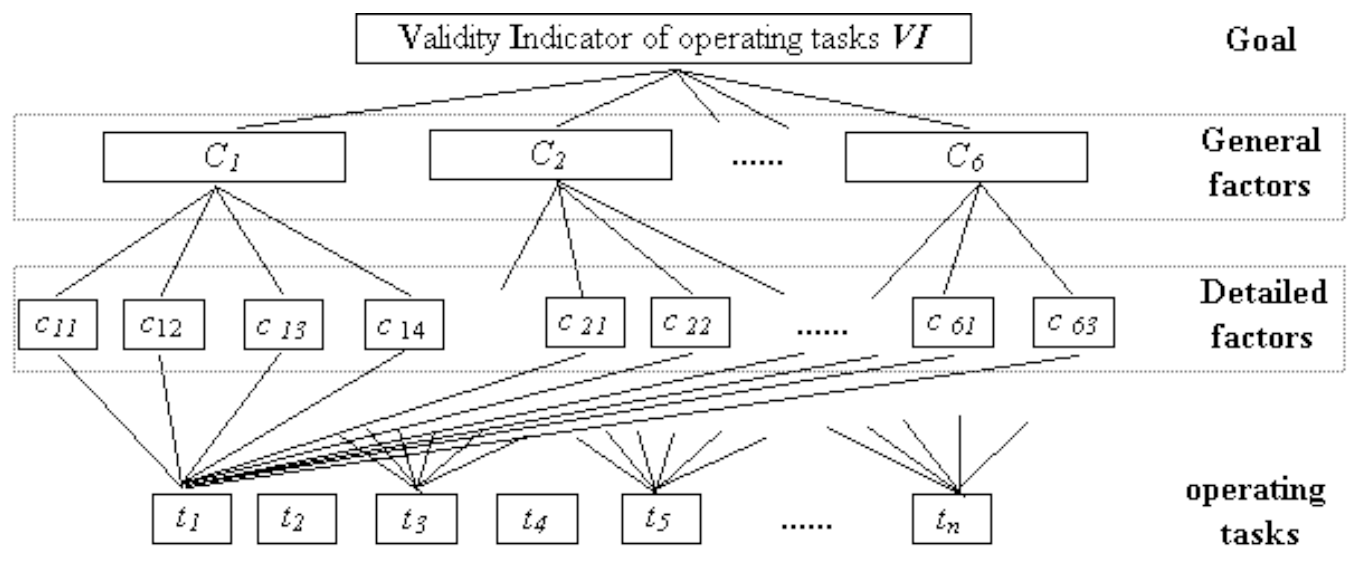

Figure 1 Hierarchic structure of factors influencing on validity of operating tasks.

In this method the value of a factor's rating is obtained from the opinions of users and experts who know the character of the estimated objects. This opinion is a result of pairwise comparison of the objects. It makes possible and easy comparative estimation of the

8

Vol. 3 Issue 12011

ISSN 1936-6744 
individual elements based on the decision-maker's preference in this problem. To compare and estimate objects, the punctual relative mark in 1-9 scale following $T$. Saaty's theory is used, presented in table 2.

The last phase of the AHP method processing was aggregation all coefficients of individual general and detailed factors in one global validity indicator of operating task permissive to the comparison of their validity.

Table 2

The AHP pair-wise comparison scale

\begin{tabular}{|c|c|c|}
\hline $\begin{array}{l}\text { Numerical } \\
\text { values }\end{array}$ & Verbal scale & Explanation \\
\hline 1 & Equal importance of both elements & Two elements contribute equally \\
\hline 3 & $\begin{array}{l}\text { Moderate importance of one element } \\
\text { over another }\end{array}$ & $\begin{array}{c}\text { Experience and judgment favor one } \\
\text { element over another }\end{array}$ \\
\hline 5 & $\begin{array}{l}\text { Strong importance of one element over } \\
\text { another }\end{array}$ & An element is strongly favored \\
\hline 7 & $\begin{array}{c}\text { Very strong importance of one element } \\
\text { over another }\end{array}$ & An element is very strongly dominant \\
\hline 9 & $\begin{array}{l}\text { Extreme importance of one element } \\
\text { over another }\end{array}$ & $\begin{array}{l}\text { An element is favored by at least an } \\
\text { order of magnitude }\end{array}$ \\
\hline $2,4,6,8$ & Intermediate values & $\begin{array}{l}\text { Used to compromise between two } \\
\text { judgments }\end{array}$ \\
\hline
\end{tabular}

\subsection{Aggregation of the weight factor coefficients}

The aggregation of preferences in the AHP method is generally executed by additive utility function, synthesizing the weight parts of individual factors (criterions) as well as value of fulfillment extent of the fractional objective function by all factors (criterions) [Saaty 1980]. According to this principle the aggregation of all factor coefficients was applied additive method with few exception.

For example, the factor related with the possibility of shift task execution identifies the option of changing the operating task execution time in schedule to the near future. This factor was defined by two detailed factors which described the combination of many different operating stage of ship and engine room but they are not alternative mutually. Only part of these operating stages combinations permitted the execution of a single operating task then both factors must be right in each considered situation. For that reason these two detailed factor coefficients $\left(c_{51}, c_{52}\right)$ were aggregated by multiplicative method. Moreover, if the there is a possibility of moving the time of operating task execution it means then the validity of it should be lower, therefore the weight factor coefficient $W C_{5}$ takes a minus sign.

Similarly with the detailed factors (repetition frequency and task executed time) of factor related with time. These two are clearly dependent then the aggregation of their coefficients $\left(c_{22}, c_{23}\right)$ has to be realized also by multiplicative method [Kaminski 2006]. Moreover, the detailed factors of factor related with possibility to omission of engine room device in operating process (number of devices, avoidance of devices in operating process) could be active only one of them in the same time (if $c_{41}=1$ then $c_{42}=0$ ).

Based on this the final form of utility function (the validity index of operating task $V I$ ) was accepted as: 


$$
\begin{aligned}
& \left.V I=W C_{1} \cdot \Gamma\left(c_{1 h} \cdot w c_{1 h}\right)+W C_{2} \cdot \mid c_{21} \cdot w c_{21}+c_{22} \cdot w c_{22} \cdot c_{23} \cdot w c_{23}\right)+ \\
& +W C_{3} \cdot \Gamma\left(c_{3 h} \cdot W c_{3 h}\right)+W C_{4} \cdot\left[\left(c_{4 h} \cdot w c_{4 h}\right)-\right. \\
& -W C_{5} \cdot \prod\left(c_{5 h} \cdot w c_{5 h}\right)+W C_{6} \cdot\left[\left(c_{6 h} \cdot w c_{6 h}\right)\right.
\end{aligned}
$$

This way of factors aggregation unifies the estimations of operating tasks validity and allows us to compare each one with remaining and make their hierarchic list, which is essential to optimal scheduling.

\section{Results of preliminary simulation}

Based on the presented model of validity rank of operating tasks in the engine room a comparative inquiry form was prepared. It was intended for experts of decision-making in the engine room like chief engineers. In this questionnaire the experts made the comparison between each of factor, the first general factors and next to the detailed factors separately in every general factor area. They estimated his preference which factor in compared pair is more important to an operating tasks validity. There was inquiry for more than twenty of chief engineers and they used the scale from table 1 for the estimation. As a result of the date processing from inquiry form was series of numeric values of weight factor coefficients.

One more question was how to aggregate many different numeric values of each validity factor coefficients received from different experts? In general there are two most popular ways to do this: by average value in arithmetic mean or geometric mean. The problem with the second option was that then the sum of the average value in general factors series and in each detailed factors series doesn't equal 1. Moreover, there was a sensible inequality between values received in these two ways and these differences were from $0,00 \%$ to $20,5 \%$. The normalized process of this values in $0-1$ range decreased this inequality to a small level, where the maximum of that value was $13,63 \%$ (two last columns in table 3 ).

$$
W C_{i(\text { norm. })}=\frac{W C_{i}}{\sum W C} \quad ; \quad w c_{i j(\text { norm. })}=\frac{w c_{i j}}{\sum w c_{i}}
$$

In order to control the results of the AHP method, the consistency ratio for each of the metrics and overall consistency for the hierarchy were calculated during data processing and verified currently. For the part of experts' judgments, the $C R$ was larger than $10 \%$. Those judgments weren't taken into account to average values of weight factors coefficients. The $C R$ for the expert's judgments, which include all coefficients, were from the field $0-10 \%$ and amount from $1.59 \%$ to $9.76 \%$. All values of weight factor coefficients are presented in table 3 . 
Table 3

Exemplary set of the operating tasks validity values obtained by the AHP methods

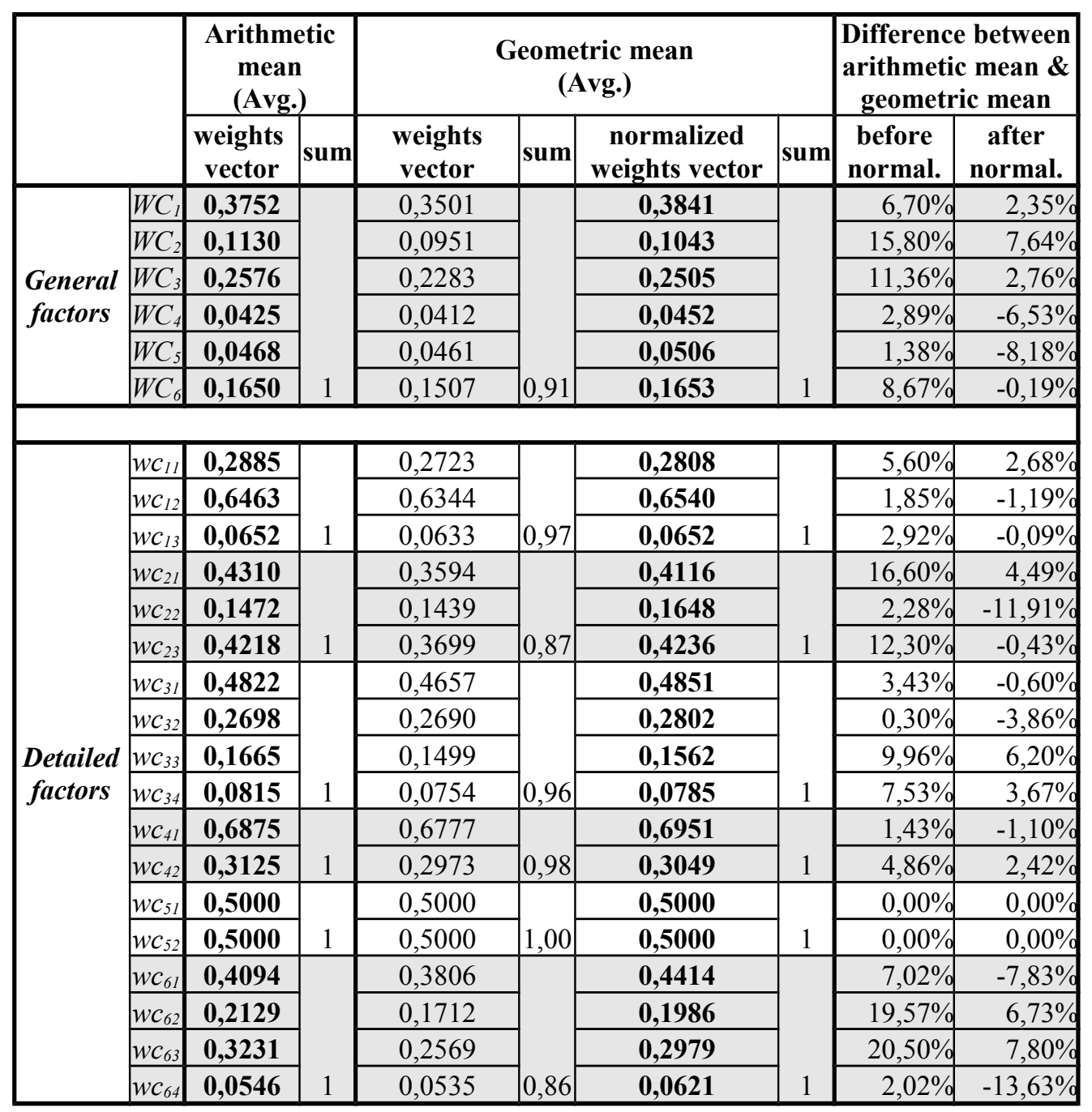

Basis on these two collections (arithmetic mean, geometric mean) of weight factor coefficients $\left(W C_{i}, w c_{i j}\right)$ and factor indexes $\left(C_{i}, c_{i j}\right)$ were accomplished a few scheduling operating tasks simulations. The simulations of scheduling were performed for the set of 12 various operating tasks (the features of the tasks were difference and chance). During these simulations were a varied number of tasks, number of operators, deadline time for a schedule, etc. For the first part of simulation a collection of arithmetic mean coefficients values was used. Next a collection of geometric mean coefficients values was used. Those two collections of result simulations were compared. The schedules received in the same conditions for both collections of weight factor coefficients were the same sequence of assigning. One difference that was observed, was the value of result quality (value of 
objective function for the best result - schedule). This kind of difference was expected because of the various value of weight factor coefficients. There was no sense to compared these values.

\section{Conclusions}

In this paper is presented an approach to solving the decision problem link to the operating tasks scheduling problem in a marine power plant. Very often in practical situations the chief engineer in the engine room has to make a hierarchy of operating tasks. This approach proposes to use the AHP method to do it. This methodology could help assess relevant criteria critically and logically and assist in sensible decisionmaking.

Processing the data of expert's preferences permits us to obtain a collection of weight factor coefficients which define the importance of a few factors in operating processes in the engine room. What's important is that, then it is necessary to collect a large number of expert's preferences to receive reliable values of all coefficients.

Two tribulations are observed, the first was: the consistency ratio $C R$ for a large number of experts answers was larger than $10 \%$, which made these answers incapacitated. The reason for this could be not enough clear explanations of the comparisons way, sense of factors, etc. The second was values divergence of weight factors coefficients received from different experts. The most probable reason for this was that then the experts have got their experience on many different types of ships. The priorities of engine room operating process there could be dissimilar and the factors forced on this process could take different weight values.

This paper does not attempt to set out an infallible priority processes or a set of some checklist for performance measurement of operating tasks in the marine power plant. The idea presented here needs to be integrated with general engine room management strategy and in this way the application of AHP should be still enhanced. This study is unique in the sense that a different methodology of operating tasks importance measurement was used. The presented model might be enlarged due to the specific of type of ships or engine rooms in which they are implemented. It is possible to build a complex decision support system connecting many models (scheduling, diagnostic, etc.) - especially focused on strategy managing in difficult situations. The most important element for successful implementation of the AHP method is explaining to decision makers the general idea of the method.

\section{REFERENCES}

Dey P.K. (2002). An integrated assessment model for cross-country pipelines. Environ Impact Assess, Rev 22:703-72.

Downarowicz J., Krause J., Sikorski M., Stachowski W. (2000). Chosen methods of ergonomics and science about exploitation. Gdańsk, Wydawnictwo PG.

Ficon K. (2006). Badania operacyjne stosowane, modele i aplikacje. Warszawa, BEL Studio. 
IJAHP Article: Kaminski/ Determination of a task's validity in the marine engine room operating process

Holguin-Veras J. (1993). Comparative assessment of AHP and MAV in highway planning: case study. J Trans Eng, 121(2):191-200.

Kaminski P., Podsiadlo A., Tarelko W. (2003). Computer-aided management of marine power plant. International Scientifically-Technical Conference "Explo-Diesel \& Gas Turbine '03”, pp.263-270.

Kaminski P., Podsiadlo A., Tarelko W. (2004). Zrodla informacji wykorzystywane w systemie wspomagajacym zarzadzanie eksploatacji siłowni okretowych. Miedzynarodowe Sympozjum Silowni Okretowych, pp.73-78.

Kaminski P. (2006). Identyfikacja elementow problemu decyzyjnego zarzadzania siłownia okretowa. „Polioptymalizacja i CAD”, pp.94-101.

Kaminski P. (2007). Model dwukryterialnej optymalizacji harmonogramu prac w siłowni okrętowej jako zadanie pakowania. Pomiary Automatyka Kontrola vol. 53, pp.25-28.

Khasnabis S., Alsaidi E., Liu L., Ellis R.D. (2002). Comparative study of two techniques of transit performance assessment: AHP and GAT. J Transp Eng 128(6):499-508.

Kukula K.,(2000). Metoda unitaryzacji zerowanej. Warszawa, Wydawnictwo Naukowe PWN.

Saaty T.L. (1980). The Analytical Hierarchy Process, New York, McGraw - Hill.

Sadiq R.,(2001). Drilling waste discharges in the marine environment: a risk-based decision methodology. PhD. Thesis, Memorial University of Newfoundland, Canada.

Suryanto H., Compton P.(2006). Learning classification taxonomies from a classification knowledge based system. http://ol2000.aifb.unikarlsruhe.de/final/HSuryanto_5.pdf.

Podsiadlo A., Tarelko W. (2006). Modelling and developing a decision-making process of hazard zone identification in ship power plants. International Journal of Pressure Vessels and Piping 83 (4), pp. 287-298.

Witkowska D. (2002). Artificial neural network and method statistical. Warszawa, Wydawnictwo C.H. Beck,

Ziara M., Nigim K., Enshassi A., Ayyub B.M. (2002). Strategic implementation of infrastructure priority projects: case study in Palestine. ASCE J Infrastructure System $8(1): 2-11$. 